Marcin Kleibert'10, Małgorzata Wojciechowska ${ }^{1,2}$, Maciej Zarębiński², Łukasz Pastwa ${ }^{3}$, Agnieszka Cudnoch-Jędrzejewska ${ }^{1}$ (1)

${ }^{1}$ Department of Experimental and Clinical Physiology, Laboratory of Center for Preclinical Research, Medical University of Warsaw, Warsaw, Poland

${ }^{2}$ Independent Public Specialist Western Hospital John Paul II, Invasive Cardiology Unit, Grodzisk Mazowiecki, Poland

IIndependent Public Specialist Western Hospital John Paul II, Cardiology Unit, Grodzisk Mazowiecki, Poland

\title{
Multiple cardiac arrests due to Lyme carditis
}

\section{Corresponding author:}

Małgorzata Wojciechowska, Department of Experimental and Clinical Physiology, Laboratory of Center for Preclinical

Research, Medical University of Warsaw, Warsaw, Poland,

e-mail: mwojciechowska2@wum.edu.pl

Medical Research Journal 2021;

Volume 6, Number 1, 71-74

10.5603/MRJ.a2021.0002

Copyright (C) 2021 Via Medica

ISSN 2451-2591

e-ISSN 2451-4101

\begin{abstract}
The most common form of Lyme carditis (LC) are different types of conduction abnormalities, especially atrioventricular $(A-V)$ blocks. In most cases the course of the disease is benign and when the patient is diagnosed and treated appropriately, even the most advanced forms of A-V block typically resolve within one week. Implantation of a permanent pacemaker is only exceptionally necessary.

We present a case of a patient with multiple cardiac arrests due to advanced A-V block. Despite the proper diagnosis of LC and targeted antibiotic therapy, the patient was completely dependent on temporary endocavitary pacing for more than one week. Finally, implantation of a permanent pacemaker was decided, however, during the next three months, A-V conduction abnormalities gradually subsided. This made us doubt whether the decision about implantation wasn't made prematurely. The solution came at a one-year follow-up visit when it turned out that ventricular stimulation reappeared.

We believe, that if A-V conduction disturbances in the course of Lyme disease persist for more than a week despite targeted antibiotic therapy, it is most likely a sign of serious and irreversible damage to the structure of the $A-V$ node. Key words: permanent pacemaker, complete atrioventricular block, Lyme disease
\end{abstract}

Med Res J 2021; 6 (1): 71-74

\section{Introduction}

Lyme disease (LD) is one of the most common tick-borne diseases. Etiologic factors are species of spirochetes (Borellia afzelli, B. garini, B. burgdorferi), which are the Gram-negative bacteria. The incubation period from infection to the onset of symptoms is usually 1-2 weeks. The first and most common presentation of the disease is erythema chronicum migrans (early localized phase, stage 1), which is seen in $70-90 \%$ of patients. It may be accompanied by unspecific symptoms of infection, such as muscle pain, fever and headache. During the next weeks occupation of different organs and systems may develop (early disseminated phase, stage 2), with most frequent affection of the skin, joints and nervous system. Chronic phase (late disseminated phase, stage 3 ) occurs after 2-3 years and most commonly refers to neurological and rheumatological complications [1-3].

Lyme carditis (LC) develops in less than $5 \%$ of patients infected, with a visible male predominance (3:1).
The cardiovascular signs occur in early disseminated disease (stage 2), usually in the third week after infection, however, they may appear between the $7^{\text {th }}$ day and the $7^{\text {th }}$ month of the illness. The pathophysiology involves infiltration of bacteria and subsequent excessive immunologic response, mainly in the connective tissue of the basal part of the interventricular septum. The majority of the cases are conduction abnormalities (90\%), mostly atrioventricular (A-V) blocks, however, pericarditis, myocarditis, cardiomyopathy and degenerative valvular disease have been occasionally observed [2, 4, 5].

If the infectious agent is identified and treated appropriately, even advanced forms of conduction abnormalities have a benign prognosis and disappear quickly, usually during one week [4]. Hospitalization and continuous cardiac monitoring are recommended for patients with second- or third-degree A-V block, first-degree A-V block with a PR interval $>300 \mathrm{~ms}$ and fluctuating bundle branch blocks.

The treatment of choice is intravenously administered antibiotics, preferably ceftriaxone, however, cefu- 
A

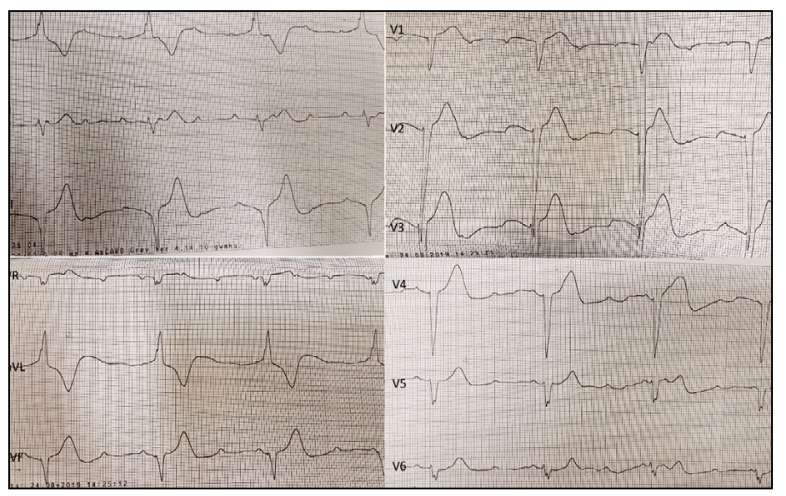

B

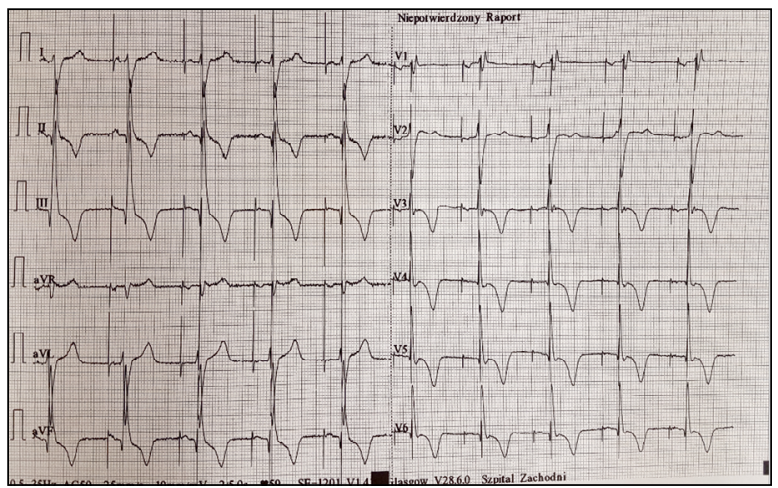

C

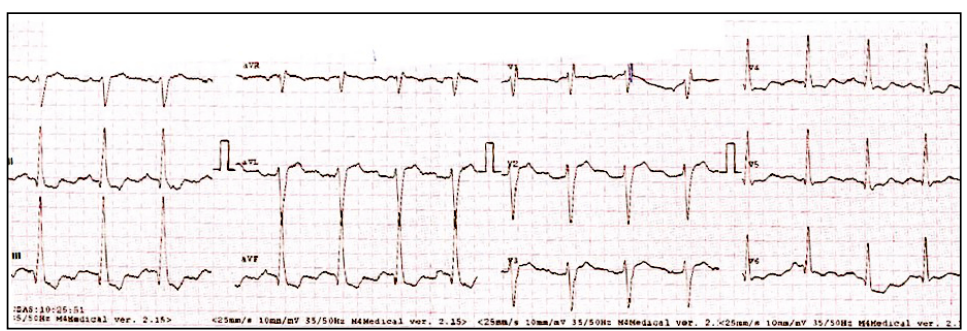

Figure 1. ECG recorded at $25 \mathrm{~mm} / \mathrm{sec}$. A. ECG on admission — third degree atrio-ventricular block, B. ECG after pacemaker implantation — dual chamber pacing, C. ECG during follow-up visit — normal sinus rhythm, left posterior fascicular block

roxime and penicillin G may be an option. Usually, two weeks of antibiotic therapy is recommended, whereas a 4-week course is recommended for chronic manifestations of Lyme disease [3, 6]. Temporary pacing may be required in unstable patients, but generally awaiting attitude is preferred. It is advisable to avoid temporary stimulation and if it is already used, it should be as short as possible [4]. Implantation of a permanent pacemaker is only exceptionally necessary [5]. Some centres use an option of applying modified transvenous temporary-permanent pacing, which is safer than temporary pacing, allows the patient to go home, and is relatively easy to remove after a few weeks. This method however it is not popular [7].

The early stage of borreliosis is evidenced by the rise in IgG titer and/or the presence of IgM [3]. There is a two-step approach in serological diagnosis, which is an initial screening test (ELISA), followed by a Western Blot carried out for reactive and equivocal ELISA samples [2, 3]. Due to delayed immune response, in the early stages of the disease serologic results may be false negative even in $50 \%$ of patients (an early diagnostic gap). Therefore negative serological tests cannot rule out the disease and in the case of clinical suspicion of LD the ELISA should be repeated, usually after 4 weeks [2]. In the late stages of Lyme disease, IgG levels are always elevated and their absence excludes the disease [2].
Diagnosis of Lyme carditis should be based primarily on the clinical presentation and an assessment of tick-exposure risk [2]. Therefore in the case of unexplained $A-V$ conduction disturbances especially in young men, empirical antibiotic treatment is recommended [6]. The disease is then confirmed by positive Borrelia serology. There are attempts to make a general algorithm for diagnosis of LC and the Suspicious Index in Lyme Carditis score (SILC) is a novel risk score, that estimates the probability of LC in patients with A-V block $[5,8]$.

\section{Case report}

A 48-year-old man, not yet treated for any reason, was admitted to the hospital after multiple cardiac arrest episodes in the course of recurrent severe bradyarrhythmia. The patient lost consciousness and stopped breathing without any preceding symptoms. Cardiopulmonary resuscitation was undertaken by family members, then continued by an ambulance team. In ECG monitoring third-degree A-V block with escape rhythm 30/min with wide QRS complexes was found (Fig. 1A). After atropine administration, the third degree A-V block turned into a hemodynamically stable second degree A-V block and the patient regained consciousness. On the way to the hospital, however, there were many recurrent episodes of advanced A-V 
Table 1. Two-steps serological diagnosis of Lyme disease: positive result of ELISA test (lgG) confirmed by Western Blot analysis (IgG against VisE and p41)

\begin{tabular}{|c|c|c|c|c|}
\hline $\begin{array}{l}\text { Screening test - } \\
\text { ELISA }\end{array}$ & & Norms & Our patient & Comments \\
\hline \multirow{2}{*}{$\begin{array}{l}\text { Detects antibodies IgG } \\
\text { and IgM against } B \text {. } \\
\text { burgdorferi s.l. }\end{array}$} & \multirow{2}{*}{$\begin{array}{l}\text { IgM level in } \\
\text { serum (RU/ml) } \\
\text { lgG level in } \\
\text { serum }(\mathrm{RU} / \mathrm{ml})\end{array}$} & $\begin{array}{l}<16 \text { - negative result } \geq 16 \mathrm{R} \text { to }<22- \\
\text { equivocal result } \geq 22-\text { positive result }\end{array}$ & 3,57 & \multirow{2}{*}{$\begin{array}{l}\text { The first step of diagnostics. } \\
\text { High sensitivity of the test, } \\
\text { which increases the risk of } \\
\text { false-positive results (cross- } \\
\text { reacting antibodies) }\end{array}$} \\
\hline & & $\begin{array}{c}<16 \text { - negative result } \geq 16 \mathrm{R} \text { to }< \\
22 \text { - equivocal result } \geq 22-\text { positive } \\
\text { result }\end{array}$ & 46 & \\
\hline $\begin{array}{l}\text { Verification test - } \\
\text { Western Blot }\end{array}$ & & Proteins & Our patient & Comments \\
\hline \multirow{6}{*}{$\begin{array}{l}\text { Detects antibodies } \\
\text { IgG and IgM against } \\
\text { a wide range of } \\
\text { proteins specific for } B \text {. } \\
\text { burgdorferi s.l. }\end{array}$} & \multirow{6}{*}{$\begin{array}{l}\text { Commonly } \\
\text { detectedproteins }\end{array}$} & p83 & - & \multirow{6}{*}{$\begin{array}{l}\text { The second step of } \\
\text { diagnostics. High } \\
\text { specificity, performed to } \\
\text { confirm infection in cases } \\
\text { of positive or equivocal } \\
\text { ELISA test }\end{array}$} \\
\hline & & $\begin{array}{l}\text { Variable major protein-like } \\
\text { sequence, expressed (VisE) }\end{array}$ & $+(\lg G)$ & \\
\hline & & p58 & - & \\
\hline & & Flagellin (p41) & $+(\lg G)$ & \\
\hline & & Outer surface protein $\mathrm{C}(\mathrm{OspC})$ & - & \\
\hline & & Decorin Binding Protein $\mathrm{A}(\mathrm{DpbA})$ & - & \\
\hline
\end{tabular}

Table 2. Atrial $(\mathrm{A})$ and ventricular $(\mathrm{V})$ pacing percentage during pacemaker control

\begin{tabular}{lc}
\hline $\begin{array}{l}\text { Time of the pacemaker } \\
\text { control }\end{array}$ & $\begin{array}{c}\text { Atrial (A) and ventricular } \\
\text { (V) pacing percentage (\%) }\end{array}$ \\
\hline Discharge from hospital & A 7, V 100 \\
One month follow-up & A 15, V 13 \\
Three-month follow-up & A 16, V 0 \\
One year follow-up & A 20, V 4 \\
\hline
\end{tabular}

block with multiple cardiac arrests. The patient was administered further doses of atropine and received external pacing. Finally, he was put into a pharmacological coma, intubated and artificially ventilated. In the hospital transvenous temporary pacing was established. The physical examination and echocardiography did not reveal any relevant abnormalities. CT pulmonary angiogram, coronary angiography and head CT scan were performed, respectively ruling out pulmonary embolism, acute coronary syndrome and central nervous system disorders. Laboratory tests showed increased C-reactive protein concentration, there were no other abnormalities. Blood culture was collected and empirical intravenous antibiotic therapy with ceftriaxone, ciprofloxacin and metronidazole was started (standard initial combination used at the authors' institution due to the patient's poor general condition including artificial ventilation). The patient was kept in a pharmacological coma and artificially ventilated for two days. Then he was woken and extubated, however, he was still completely dependent on endocavitary pacing. For the next few days, he presented agitation and confusion, which was probably associated with multiple cardiac arrests and hypoxia to the central nervous system.
While taking a detailed medical history from the patient's wife, she could recall that he had been exposed to multiple tick bites about a month ago and 2 weeks ago she observed erythema on the skin of his thigh, the trace of which was still present at close examination. The serological diagnostics for LD was ordered. After 3 days ( $5^{\text {th }}$ day of hospitalization) positive results were received - the level of specific IgG but not IgM was elevated. The results were confirmed in Western Blot analysis (Tab. 1). In subsequent serological tests, that were repeated after a week, IgM was again negative but increasing IgG titers were observed. Finally, LD with heart involvement was recognized so intravenous ceftriaxone therapy ( $2 \mathrm{~g}$ iv once daily) was continued for 2 weeks. As blood cultures appeared to be negative, two other antibiotics were discontinued.

Despite several days of ceftriaxone therapy, the patient was completely dependent on endocavitary pacing. Finally, for suspicion of permanent damage to the conductive system and the history of multiple cardiac arrest episodes, on the $10^{\text {th }}$ day of hospitalization, a decision was made to implant a permanent pacemaker (Fig. 1B). The pacing percentage in atrial and ventricular channels at discharge $\left(14^{\text {th }}\right.$ day of hospitalization and antibiotic therapy) was 7 and $100 \%$ respectively. In pacemaker follow-up after one and three months, gradual $\mathrm{A}-\mathrm{V}$ block regression and resolution of the pacemaker's participation in A-V conduction were observed, however, in a one-year follow-up, ventricular pacing again became visible (Tab. 2). In ECG made during the follow-up visits, normal sinus rhythm with a left posterior fascicular block (LPFB) was present, it is not certain, however, whether it is a remnant of the disease or the patient had it before (Fig. 1C). 


\section{Discussion}

Plenty of cases of patients with advanced A-V blocks were published, but in a few cases, the course of the disease was so dramatic as in the presented patient case $[9,10]$. In the majority of cases, antibiotic therapy was the only method of treatment and there was no need for temporary pacing nor permanent pacemaker implantation. In a systematic review made by Besant $\mathrm{G}$ et al. high-degree A-V block resolved in $94.3 \%$ of cases, with a median time to resolution of 5 days (3-9). A permanent pacemaker was implanted in $12.5 \%$ of patients, but in half of them, A-V block resolved after a course of antibiotics, and the pacemaker was removed or no longer required [8]. In another review, permanent pacing was necessary for $4.4 \%$ of patients [9]. Therefore, because of a known good prognosis and resolution of conduction abnormalities in most cases, the decision to implant a permanent pacemaker was not easy and not obvious. The pros were: extremely severe symptoms on admission, lack of IgM (not really an early stage of the disease?) and the need for temporary pacing for 10 days despite proper treatment. The latter mentioned might indicate permanent $\mathrm{A}-\mathrm{V}$ conduction damage and additionally was associated with the patient's impaired mobility due to the risk of electrode dislocation and possible drawbacks, including infectious complications and mechanical, like perforation of the myocardium. As on discharge (14 $4^{\text {th }}$ day of antibiotic therapy), the patient was still pacemaker dependent, the decision seemed right at first, however, during the next three months A-V conduction disturbances gradually resolved. As there are no general guidelines concerning this topic, a question came up, whether the performed management was optimal. Should the decision about pacemaker implantation be deferred? Also, another puzzling issue arose - should pacemaker removal be considered since A-V block resolved? Taking into account that the residual LPFB might be a remnant of LC - would it be fully safe to remove the pacemaker? Does LPFB increase the patient's future risk of A-V block recurrence? No such data are available, which made the decision more difficult. The solution came with a follow-up visit a year after pacemaker implantation when it turned out that despite pacemaker settings promoting the patient's ventricular beats (interval between an atrial paced or sensed event and the ventricular pacing pulse was about $350 \mathrm{~ms}$ ), the ventricular pacing was again pres- ent. It was $4 \%$, which seems a small percentage, but actually, it is enough to lead to sudden cardiac arrest.

\section{Conclusions}

The most common form of LC is A-V blocks, which usually disappear during the first few days of antibiotic therapy. In some cases, however, the A-V conduction disturbances are severe, they last longer and can be even the cause of sudden cardiac death. Persistence of $A-V$ blocks despite antibiotic therapy for more than one week rather indicate permanent damage to the structures of the conducting system and may indicate the need for permanent pacing. As there are no guidelines concerning the timing for the pacemaker implantation, management of the most severe patients should be individual.

\section{Acknowledgements: None.}

\section{Conflict of interest: The authors declare no conflict of interest.}

\section{References}

1. Stanek G. Wormser G, Gray J, et al. Lyme borreliosis. The Lancet. 2012; 379(9814): 461-473, doi: 10.1016/s0140-6736(11)60103-7.

2. Scheffold N, Herkommer B, Kandolf R, et al. Lyme carditis--diagnosis, treatment and prognosis. Dtsch Arztebl Int. 2015; 112(12): 202-208, doi: 10.3238/arztebl.2015.0202, indexed in Pubmed: 25838022

3. Stanek G, Strle F. Lyme borreliosis-from tick bite to diagnosis and treatment. FEMS Microbiol Rev. 2018; 42(3): 233-258, doi: 10.1093/femsre/fux047, indexed in Pubmed: 29893904.

4. Lelovas P, Dontas I, Bassiakou E, et al. Cardiac implications of Lyme disease, diagnosis and therapeutic approach. Int J Cardiol. 2008; 129(1): 15-21, doi: 10.1016/j.jijcard.2008.01.044, indexed in Pubmed: 18508142.

5. Yeung C, Baranchuk A. Diagnosis and Treatment of Lyme Carditis: JACC Review Topic of the Week. J Am Coll Cardiol. 2019; 73(6): 717-726, doi: 10.1016/j jacc 2018.11.035, indexed in Pubmed: 30765038.

6. Wormser GP, Dattwyler RJ, Shapiro ED, et al. The clinical assessment, treatment, and prevention of lyme disease, human granulocytic anaplasmosis, and babesiosis: clinical practice guidelines by the Infectious Diseases Society of America. Clin Infect Dis. 2006; 43(9): 1089-1134, doi: 10.1086/508667, indexed in Pubmed: 17029130.

7. Wang $\mathrm{C}$, Chacko S, Abdollah H, et al. Treating Lyme carditis high-degree AV block using a temporary-permanent pacemaker. Ann Noninvasive Electrocardiol. 2019; 24(3): e12599, doi: 10.1111/anec.12599, indexed in Pubmed: 30265432

8. Besant G, Wan D, Yeung C, et al. Suspicious index in Lyme carditis: Systematic review and proposed new risk score. Clin Cardiol. 2018; 41(12): 1611-1616, doi: 10.1002/clc.23102, indexed in Pubmed: 30350436.

9. Forrester JD, Mead P. Third-degree heart block associated with lyme carditis: review of published cases. Clin Infect Dis. 2014; 59(7): 996-1000, doi: 10.1093/cid/ciu411, indexed in Pubmed: 24879781.

10. Kashou AH, Braiteh N, Kashou HE. Reversible atrioventricular block and the importance of close follow-up: Two cases of Lyme carditis. J Cardiol Cases. 2018; 17(5): 171-174, doi: 10.1016/j.jccase.2018.01.001, indexed in Pubmed: 30279884. 